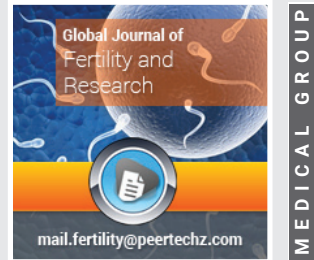

\title{
Chronic endometritis in In-Vitro fertilization failure patients
}

\author{
Afaf T Elnashar ${ }^{1 *}$ and Mohamed Sabry ${ }^{2}$ \\ ${ }^{1}$ Department of Pathology, Sohag University, Egypt \\ ${ }^{2}$ Department of Obstetrics and Gynecology, Sohag University, Egypt
}

Received: 28 October, 2020

Accepted: 20 January, 2021

Published: 21 January, 2021

*Corresponding author: Afaf T Elnashar, Department of Pathology, Sohag University, Egypt, Tel: 0201023438794; E-mail: elnasharafaf@yahoo.com; afaf-elnashar@med.sohag.edu.eg

Keywords: CD138; Syndecan-1; Chronic endometritis; IVF

https://www.peertechz.com

\section{Abstract}

Introduction: Chronic Endometritis (CE) is a common cause of infertility in asymptomatic patients and its diagnosis and treatments improved assisted reproduction technique outcome in most of the specialized centers. Diagnosis of CE in endometrial biopsy by Hematoxylin and Eosin (H\&E) stain is hard to identify chronic inflammatory cells from the stroma and the use of plasma cells-specific stains is helpful.

Aim of the work: Evaluation of the use of CD138 in the identification of plasma cells in endometrial biopsy of patients with previous IVF trial failure.

Material and methods: Hysteroscopic and curettage endometrial biopsies from fifty-five females with previous IVF trial failure were stained with H\&E and CD138 immunostaining for detection of plasma cells.

Results: Plasma cells were identified in $52.7 \%$ of cases by H\&E and in $6 / 55$ by CD138 immunostaining. CD138 is more sensitive in detecting plasma cells in endometrial biopsy than H\&E stain. There was a significant statistical correlation between CE and abnormal uterine bleeding, abortion and primary infertility ( $P>0.5)$.

Conclusions: Diagnosis of CE is helpful in infertility patients with IVF trial failure to improve the outcome of the maneuver. CD138 is more sensitive for plasma cells especially in endometrial biopsies than H\&E.

\section{Introduction}

In spite of the fact that disordered uterine function is considered to have a major impact on the possibilities to conceive through IVF, conventional infertility investigations, including ultrasound and Hysterosalpingography (HSG) may miss subtle intrauterine lesions. After hysteroscopy maneuver before performing IVF, the incidence of undiagnosed intrauterine lesions has been demonstrated to be at the range of $11-45 \%$ [1]. One of these abnormalities is Chronic Endometritis (CE) that is often asymptomatic or can be accompanied by nonspecific symptoms. The use of histopathology in detection of plasma cells in the endometrial curettage is essential for the diagnosis of CE [2].

Chronic endometritis may interfere with receptivity of the endometrium and therefore, leads to infertility because $\mathrm{CE}$ is characterized by an abnormal pattern of lymphocytic infiltration and consequently, an abnormal endometrial microenvironment [3]. In a study conducted in 2014, it was demonstrated that $\mathrm{CE}$ is a frequently found in females with repeated abortions, and consequently, women who took antibiotic therapy had a significantly higher rate of successful pregnancies compared to those without treatment [4]. Mainwile, CE was a pathological diagnosis in about $30 \%$ of females with repeated implantation failure at IVF and those that were diagnosed as CE had about (11.5\%) lower rates of implantation after an IVF cycle [5].

On the other hand, Kasius, et al. reported a minimal clinical implication of CE on fertility after IVF and they documented CE in only ( $2 \%)$ of asymptomatic women with infertility. They concluded that pregnancy rate after IVF was not affected by CE [6].

Syndecan-1 or CD138 is a well-known trans-membrane heparan sulfate proteoglycan family member, which acts as a receptor at extracellular matrix and is involved in different cellular functions, mainly cell-cell and cell-matrix adhesion. Expression of CD138 is observed normally on the surface of mature epithelial cells; however, stromal expression was also detected in developing tissues. In the hematopoietic system, expression of $\mathrm{CD} 138$ is thought to be restricted to normal and 
malignant plasma cells. Based on messenger RNA studies, high levels of CD138 was restricted to the precursor B-cell and plasma cell stages of B-cell differentiation [7].

B-cells constituted about $<1 \%$ of all leukocytes in normal endometrium. B-cell infiltration is rarely detected, in the functional layer of the endometrium but is found mainly in the basal layer, as central cells in the lymphocyte aggregates are surrounded by macrophages and many CD8+ T-cells. In chronic non-specific endometritis, a large number of B-cells focally infiltrates both the endometrial stroma and glandular epithelium [8].

Accumulating evidence documented the efficiency of antibiotic oral therapy to eliminate endometrial stromal plasma cells in patients with $\mathrm{CE}$. On the other hand, it is unclear to the investigators on how antibiotic treatment changes endometrial microbial profiling in CE. Several studies documented the abnormal expression of many pro-inflammatory chemical mediators involved in B-cell extravasation in CE. Selectin plays an important role in tethering/rolling of circulating B-cells on endothelial cells. While Selectin E is not detected in normal endometrium, in $\mathrm{CE}$ endometrial vascular endothelial cells express this B-cell adhesion molecule. Moreover, endometrial microvascular endothelial cells specifically expressed CXCL-13 in $\mathrm{CE}$, which is a chemo-attractant that activates the adhesion molecules on B-cells and endothelial cells. Endometrial glandular epithelial cells with CE also expressed CXCL-1, a chemokine involved in B-cell migration [9]. All these findings suggest that local microbial infection in the endometrium stimulates the immune responses, which potentially retrieve circulating B-cells into the endometrial stromal and the glandular areas. The migrating B-cells may differentiate into plasma cells within the endometrial stroma. It was found that endometrial stromal plasma cells express multiple immunoglobulin subclasses (IgM, IgA1, IgA2, IgG1, and IgG2) with a predominant IgG2. These excessive mucosal antibodies affect the process of embryo implantation negatively [10].

Endometrial micro polyposis was reported to be associated with endometrial stromal edema, thickening, and periglandular hyperemia noticed with $\mathrm{CE}$. These lesions cannot be detected by ultrasonography or hysterosalpingography but can be diagnosed by fluid hysteroscopy. Hysteroscopy therefore has an important role in the diagnosis of CE in Gynecology and Obstetrics practice. On the contrary, local bacterial examination alone is unlikely to be useful in the diagnosis of CE [11].

A small number of plasma cells in the endometrial curettage biopsy are difficult to be identified in the H\&E-stained sections. In addition, the histological changes in the proliferative and secretory phases of endometrium can also interfere with the detection of plasma cells and the diagnosis of CE. During late menstruation or early proliferative endometrium, significant lymphocyte infiltrations, mitosis in the stroma, and plasma cell-like stromal cells, appear in the endometrial tissue. These can simulate plasma cells in the endometrial tissue and interfere with the diagnosis of CE [12].

\section{Aim of the work}

To study the use of immunohistochemical expression of CD138 in the diagnosis of Chronic Endometritis (CE) which is considered as a risk factor for assisted reproduction (IVF) failure patients.

\section{Materials and methods}

In order to uncover the controversial role of CE in IVF failure women, we evaluated the incidence of CE by both hysteroscopy and histopathology in 55 women who experienced IVF-failure (failure to get pregnant). The study protocol was accepted by the Sohag Medical ethical committee and every female signed a written consent for the maneuvers (both hysteroscopy and endometrial biopsy that were performed as a part of workup for IVF-ET second trial). The cases, who have been diagnosed with CE in the study were given the appropriate antimicrobial drugs and were given a period of 6 months to 1 year before starting another trial of IVF. Specific exclusion criteria of the study cases include: 1 . Females with intrauterin contraceptive devices, (as it is characterized by prolonged plasma cell accumulation even after their removal from the uterine cavity). 2. Endometriosis. 3. Post-gestational long-term retention of products of conception. 4. Acute suppurative endometritis (recognized as neutrophil invasion and micro abscess formation in the endometrium). 5. Uterine and/or cervical tumors. 6. Previous recent treatments with chemotherapy. 6. Specific disease as hypothyroidism, tuberculosis, diabetes, liver or renal chronic diseases. After hysteroscopy, endometrial biopsies were collected from 55 cases of IVF trial failure females, specifically from the endometrial micro polyposis areas. It was fixed immediately by immersion in $10 \%$ neutral formaldehyde for fixation. After ethanol gradient dehydration, the endometrial tissues were cleared with Xylene, immersed in paraffin for embedding, and $4 \mu \mathrm{m}$ serial sections were cut. All paraffin blocks were stained with routine H\&E and Geimsa stains for detection of plasma cells and diagnosing CE (Geimsa stain was used to confirm the diagnosis of CE and the presence of plasma cell detected by H\&E as the plasma cells were stained red in color with Geimsa stain for easy detection). Paraffin-embedded, endometrial tissue blocks were cut and mounted on 3-aminopropyl-triethoxysilane-coated slides and stained using Syndecan-1 (monoclonal mouse antihuman CD 138; Clone M115, Dako) at a dilution 1/50 for $2 \mathrm{H}$, at room temperature). The immunostained slides were scored for the presence of membranous immunostaining of plasma cells using light microscopy, in at least $10 \mathrm{HPF}$. Each section was graded as Negative (-): when no plasma cells stained with CD138; Positive $(+)$ when $<5$ plasma cells were detected; $(++)$ when 5-10 plasma cells were detected, and $(+++)$ when $>10$ plasma cells were stained (13). The secondary histologic features of $\mathrm{CE}$ like gland architectural irregularity, spindling of the stroma, stromal edema and/or hemorrhage with the presence of plasma cells were considered. All immunohistochemical and H\&E findings were statistically analyzed using SPSS software version 14 and Fischer's exact tests. Value of $\mathrm{P}<0.05$ was considered significant [14]. 


\section{Results}

Fifty-five women with a history of previous IVF failure were included in this study with age range 18-45 years with mean age 31.5 years. Twenty-seven cases were diagnosed as primary infertility, while 28 cases complained of secondary infertility. Proliferative endometrium was seen in 32 cases and secretory endometrium was seen in 23 cases. Seven cases had previous abortions, and 27 cases complained of prolonged abnormal uterine bleeding. CE was diagnosed in 29/55, (52.7\%) by H\&E and Geimsa stains and in 6 cases (10.9\%) by CD138 immunostaining. A previous history of abnormal uterine bleeding episodes, abortion and primary infertility due to fallopian tube obstruction were statistically correlated with CE $(\mathrm{P}<0.05)$. CD138 immunostaining expression had no statistically significant correlation with age of the patient $(\mathrm{p}<$ $0.7)$, secondary infertility $(\mathrm{P}<0.05)$, or the type of endometrium either proliferative or secretory $(\mathrm{P}<0.6)$. CD138 is a more sensitive test (sensitivity 66.7\%) but less specific for plasma cells (specificity 48.9\%) while routine H\&E staining was detected to be less sensitive than $\mathrm{CD} 138$ (sensitivity 55.7\%) and equal to $\mathrm{CD} 138$ as specific for plasma cells detection (specificity $50 \%$ ). The use of H\&E together with Geimsa stain is sensitive and specific for detection of plasma cells in endometrial biopsy as CD138 Tables 1,2 and Figures 1,2.

\section{Disscussion}

Infertility is a relatively common gynecological problem. Relevant studies have shown that the incidence of chronic endometritis (CE) in infertile patients ranges from $0.2-46 \%$ [15].

Chronic endometritis (CE) is a local non-specific inflammatory disease characterized by abnormal plasma cells infiltration in the endometrial stromal areas. In the present

Table 1: The clinicopathological characteristics of the study groups.

\begin{tabular}{|c|c|c|c|c|}
\hline & NO & CE + with H\&E & CE+ with CD138 & P value \\
\hline Age range & $20-45$ & & & \\
\hline 1ry Infertility & 27 & 13 & 3 & 0.03 \\
\hline 2dry infertility & 28 & 16 & 3 & 0.06 \\
\hline Tubal factor & 19 & 13 & & 0.005 \\
\hline Previous miscarriage & 7 & 4 & & 0.005 \\
\hline AUB & 27 & 16 & 3 & 0.002 \\
\hline Proliferative E & 32 & 16 & 3 & \\
\hline Secretory E & 23 & 13 & $6 / 55(12 \%)$ & \\
\hline CE & & $29(52.7 \%)$ & & \\
\hline
\end{tabular}

Table 2: The sensitivity and specificity of both H\&E and CD128 in detection of plasma cells in CE.

\begin{tabular}{|c|c|c|}
\hline & H\&E & CD138 \\
\hline Sensitivity & $55.7 \%$ & $66.7 \%$ \\
\hline Specificity & $50 \%$ & $48.9 \%$ \\
\hline +ve predictive value & $52.7 \%$ & $13.8 \%$ \\
\hline -ve predictive value & $89.7 \%$ & $92.3 \%$ \\
\hline
\end{tabular}

- Positive negative

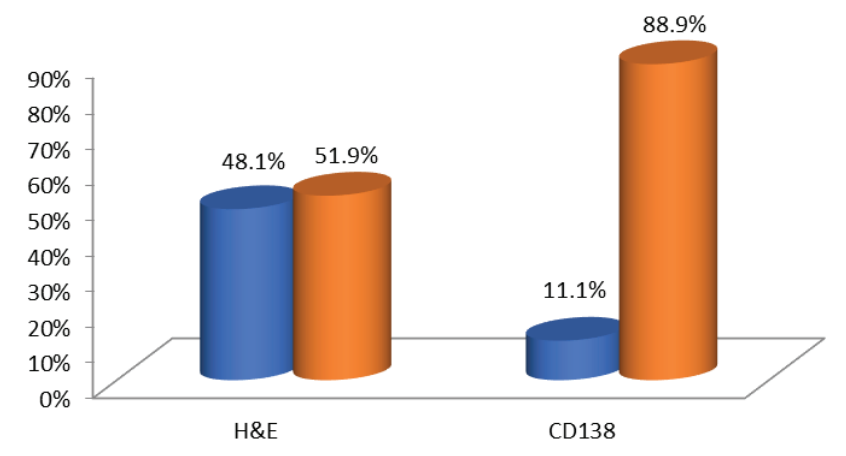

Figure 1: The representation of H\&E and CD138 positive plasma cells in 1ry infertility cases.

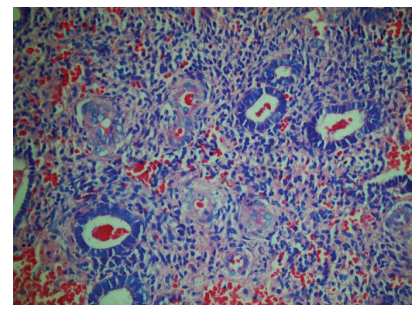

A

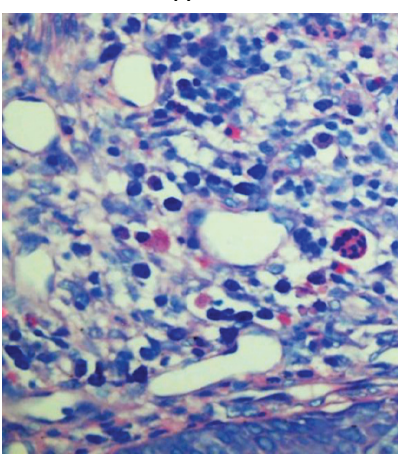

C

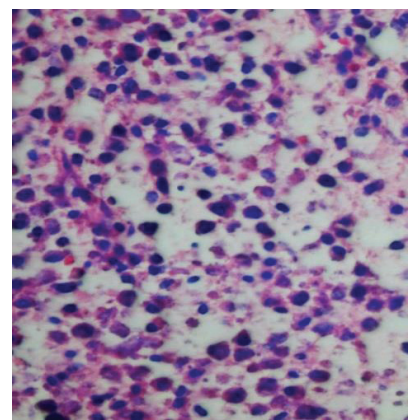

$\mathrm{E}$

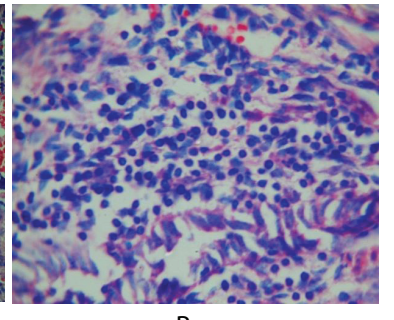

B

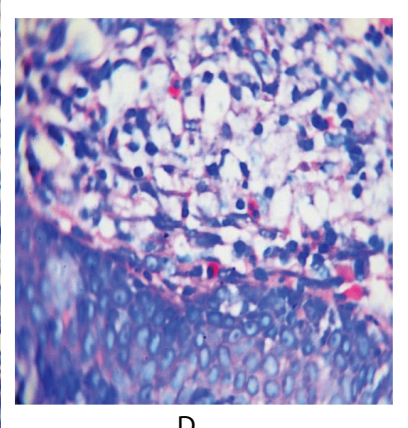

D

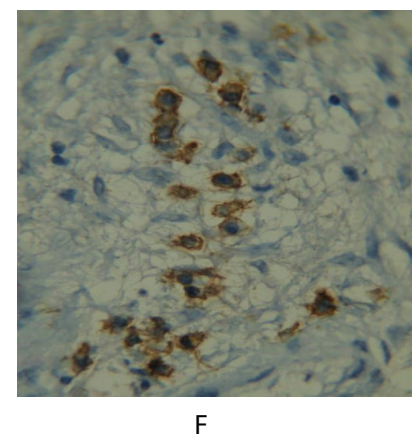

Figure 2: A proliferative endometrium with $\mathrm{CE}(\mathrm{H} \& \mathrm{E}) \mathrm{X} 40)$.

B: Endometrial infiltrate with B-cells stained by Geimsa stain (X 100).

C: D: CE with plasma cells stained red by Geimsa stain (X 100).

E: Plasma cells stained with H\&E in a case with previous abortion (X 200).

F: Plasma cells membranous immunostaining by CD138 (X 200).

study CE was detected by H\&E in $52.7 \%(29 / 55)$ and in $12 \%$ by $\mathrm{CD} 138$ of the studied cases that experienced implantation failure after IVF trial. There was a significant statistical correlation between $\mathrm{CE}$ and specific risk factors as abnormal uterine bleeding, previous abortion, and primary infertility caused by tubal factor ( $\mathrm{p}>0.5)$. 
Recent studies have disclosed the association between $\mathrm{CE}$ and reproductive failure. Chronic endometritis was identified in $30 \%$ of the patients with repeated implantation failure after in vitro fertilization-embryo transfer, in $28 \%$ of the patients with unexplained infertility, and in $12 \%$ of the patients with unexplained recurrent miscarriages [16-18].

An earlier study on the underlying causative agents in CE found that the microorganisms detected more frequently in the endometrium with CE are common bacteria [Streptococcus species (27\%), Escherichia coli (11\%), Enterococcus faecalis $(14 \%)$ ], mycoplasma species (Mycoplasma Genitalium (15\%) and Ureaplasma Urealyticum (11\%). The bacterial flora in the endometrial tissue culture was inconsistent with those in the vaginal or endocervical swab culture in patients with CE [19].

In the present study a mixture of bacterial (Streptococci species), Fungal (Candida Albicans) and viral (HPV) were detected in the cervical swab examination of the studied cases but none of these showed a statistically significant correlation with CE. A recent study demonstrated that $\mathrm{CE}$ is a common finding in women complaining of repeated unexplained implantation failure. The reproductive outcome at IVF was significantly improved in those patients in whom antibiotic treatment was able to normalize both hysteroscopic and histologic endometrial pattern [20].

In agreement with our results, it was suggested in a recent study in 2016 that a previous prolonged menstrual bleeding episode, an abortion history or fallopian tube obstruction were associated with the pathogenesis of chronic endometritis and were independent risk factors of CE. They have shown that among infertile patients, the prevalence of CE was $27.96 \%$ and among patients who received assisted reproductive technology, the pregnancy rate in the control group ( $31.3 \%$ ) was significantly higher than that of the chronic endometritis group (7.7\%) $(\mathrm{P}=0.017<0.05)$, indicating that chronic endometritis may be one of the causes of infertility [12]. Chronic endometritis was detected in $14 \%$ of women with repeated implantation failure and in $27 \%$ in women with recurrent pregnancy losses in a more recent study in 2016 [21].

Although theassociationbetweenCE(plasmacellsinfiltration of the endometrium) and abnormal uterine bleeding still remains to be established, there was a statistically significant correlation between CE and abnormal uterine bleeding ( $\mathrm{P}>$ 0.5) in our study. It was demonstrated that endometrium with CE uniquely expresses the chemokines CXCL-1, CXCL13 and adhesion molecules Selectin E, implicating that local $\mathrm{B}$-cells are recruited from endometrial microcirculation and differentiate in-situ into plasma cells. Such unusual leucocyte composition in CE may disrupt the integrity of the epithelial lining and cause endometrial shedding resulting in Abnormal Uterine Bleeding (AUB) [17].

In the present study, CE was detected in $52.7 \%$ of cases which is considered to be high rate compared to a cohort study of 395 cases of infertility with a history of two or more early pregnancy losses, CE was found in $9 \%$ of cases and the cure rate was $100 \%$ after a course of antibiotics and subsequent live birth rate was $88 \%$ [22]. Another study found that $\mathrm{CE}$ was detected in $30.3 \%$ of patients with recurrent implantation failure and they concluded that recurrent implantation failure warrants investigations on $\mathrm{CE}$ as a contributing factor [16]. This discrepancy of CE incidence rate can be explained on the bases of a lower socioeconomic standard in most of the developing countries including Egypt that did not provide regular medical surveillance programs for early diagnosis and treatment of CE especially in asymptomatic infertile women.

In the present study CD138 showed sensitivity and specificity for detection of plasma cells in endometrial biopsy of $66.7 \%$ and $48.9 \%$ respectively in agreement with a similar study that evaluated Syndecan-1 (CD138) immunohistochemical staining of endometrial biopsies in 107 women with repeated pregnancy losses. They concluded that $\mathrm{CD} 138$ provided increased sensitivity for chronic endometritis diagnosis compared to H\&E staining [22].

On the other hand, a prevalence of CE in 606 patients with an adequate biopsy was $2.8 \%$ in an earlier study with a cumulative live birth rate (including spontaneous pregnancies) did not significantly differ between patients with or without $\mathrm{CE}$ (76\% versus $54 \%)$ [2].

Diagnosis and treatment of CE significantly improves implantation rate in patients undergoing IVF-ET (In Vitro Fertilization and Embryo Transfer) in a study that concluded CE to be found in $40.7 \%(11 / 27)$ of women [23] While in an earlier study, CD138-positive plasma cells were detected in 18 cases of $\mathrm{CE}$ while none of the 25 cases of abnormal uterine bleeding showed immunostaining for CD138 [24]. Kannar, et al. diagnosed CE in 3/50 cases by H\&E and in 22/50 cases by immunohistochemistry technique [25], while in Hartman, et al. case plasma cells were stained by H\&E in 29/100 and by CD138 in 90/100 cases of CE [26]. The different and variable correlation between $\mathrm{CE}$ and infertility risk factors as abnormal uterine bleeding in the studies necessitated a further work with larger groups of patients using cohort studies.

\section{Conclusion}

- Syndecan-1 (CD138) is a sensitive immunohistochemical marker for detection of plasma cells in CE than the routine H\&E and Geimsa stains especially in asymptomatic infertility patients. Larger cohort studies are needed in the future to evaluate the role of CE in patients with IVF and implantation failure to improve the outcome of these techniques.

\section{References}

1. Fatemi HM, Kasius JC, Timmermans A, van Disseldorp J, Fauser BC, et al. (2010) Prevalence of unsuspected uterine cavity abnormalities diagnosed by office hysteroscopy prior to in vitro fertilization. Hum Reprod 25: 1959-1965. Link: https://bit.ly/3qAwq4P

2. Kasius JC, Fatemi HM, Bourgain C, Sie-Go DMD, Eijkemans RJC, et al. (2011) The impact of chronic endometritis on reproductive outcome. Fertil Steril 96 : 1451-1456. Link: https://bit.ly/3bTCMbk

3. Matteo M, Cicinelli E, Greco P, Massenzio F, Baldini D, et al. (2009) Abnormal pattern of lymphocyte subpopulations in the endometrium of infertile women with chronic endometritis. Am J Reprod Immunol 61: 322-329. Link: https://bit.ly/3c1kk0N 
4. Cicinelli E, Matteo M, Tinelli R, Pinto V, Marinaccio M, et al. (2014) Chronic endometritis due to common bacteria is prevalent in women with recurrent miscarriage as confirmed by improved pregnancy outcome after antibiotic treatment. Reprod Sci 21: 640-647. Link: https://bit.ly/3nUyMtC

5. Quaas A, Dokras A (2008) Diagnosis and treatment of unexplained infertility Rev Obstet Gynecol 1: 69-76. Link: https://bit.ly/39R4vab

6. Kasius JC, Broekmans FJM, Sie-Go DM, Bourgain C, Eijkemans MJC, et al. (2012) The reliability of the histological diagnosis of endometritis in asymptomatic IVF cases: a multicenter observer study. Hum Reprod 27: 153158. Link: https://bit.ly/3oZtU80

7. O'Connell FP, Pinkus JL, Pinkus GS (2004) CD138 (Syndecan-1) A plasma cell marker, immunohistochemical profile in hematopoietic and non- hematopoietic neoplasms Am J Clin Pathol 121: 254-263. Link: https://bit.ly/2LOW7Qj

8. Kitaya K, Yamada H (2011) Pathophysiological roles of chemokines in human reproduction: an overview. Am J Reprod Immunol 65: 449-459. Link: https://bit.ly/3ivwkZx

9. Kitaya K, Yasuo T (2010) Aberrant expression of Selectin E, CXCL1, and CXCL13 in chronic endometritis. Mod Pathol 23: 1136-1146. Link: https://bit.ly/3ivwwrJ

10. Kitaya K, Matsubayashi H, Yamaguchi K, Nishiyama R, Takaya Y, et al. (2016) Chronic endometritis: Potential cause of infertility and obstetric and neonatal complications. Am J Reprod Immunol 75: 13-22. Link: https://bit.ly/35YHTmT

11. Cicinelli E, Resta L, Nicoletti R, Zappimbulso V, Tartagni M, et al. (2005) Endometrial micro polyps at fluid hysteroscopy suggest the existence of chronic endometritis. Hum Reprod 20: 1386-1389. Link: https://bit.ly/2NnaZGb

12. Chen YQ, Fang RL, Luo YN, Luo CQ (2016) Analysis of the diagnostic value of CD138 for chronic endometritis, the risk factors for the pathogenesis of chronic endometritis and the effects of chronic endometritis in pregnancy: A cohort study. BMC Women's Health 16: 60. Link: https://bit.ly/3iuTb7w

13. Al-Quran SZ, Yang L, Magill JM, Braylan RC, Douglas-Nikitin VK (2007) Assessment of bone marrow plasma cell infiltrates in multiple myeloma: the added value of CD138 immunohistochemistry. Human Pathol 38: 1779-1787. Link: https://bit.ly/3p4BbDp

14. Florkowski CM (2008) Sensitivity, specificity, receiver-operating characteristic (ROC) curves and likelihood ratios: communicating the performance of diagnostic tests. Clin Biochem Rev 29: S83-S87. Link: https://bit.ly/2Y9evWZ

15. Carvalho FM, Aguiar FN, Tomioka R, de Oliveira RM, Frantz N, et al. (2013) Functional endometrial polyps in infertile asymptomatic patients: a possible evolution of vascular changes secondary to endometritis. Eur J Obstet Gynecol Reprod Biol 170: 152-156. Link: https://bit.ly/38Z86ni

16. Johnston-MacAnanny EB, Hartnett J, Engmann LL, Nulsen JC, Sanders MM, et al. (2010) Chronic endometritis is a frequent finding in women with recurrent implantation failure after in vitro fertilization. Fertil Steril 93: 437-441. Link: https://bit.ly/35SWYGr

17. Kitaya K (2011) Prevalence of chronic endometritis in recurrent miscarriages. Fertility and Sterility 95: 1156-1158. Link: https://bit.ly/3sFzRJp

18. McQueen DB, Benardi LA, Stephenson MD (2014) Chronic endometritis in women with recurrent early pregnancy lose and/ or fetal demise. Fertil Steril 101: 1026-1030. Link: https://bit.ly/35W50Dn

19. Cicinelli E, De Ziegler D, Nicoletti R, Colafiglio G, Saliani N, et al. (2008) Chronic endometritis: correlation among hysteroscopic, histologic, and bacteriologic findings in a prospective trial with 2190 consecutive office hysteroscopies Fertil Steril 89: 677-684. Link: https://bit.ly/3o2nJi5

20. Cicinelli F, Matteo M, Tinelli R, Lepera A, Alfonso R, et al. (2015) Prevalence of chronic endometritis in repeated unexplained implantation failure and the IVF success rate after antibiotic therapy. Hum Reprod 30: 323-330. Link: https://bit.ly/38XbAXu

21. Bouet PE, El-Hachem H, Monceau E, Gariepy G, Kadoch IJ, et al. (2016) Chronic endometritis in women with recurrent pregnancy loss and recurrent implantation failure: Prevalence and role of office hysteroscopy and immunohistochemistry in diagnosis. Fertil Steril 105: 106-110. Link: https://bit.ly/3bREzOl

22. McQueen DB, Perfello CO, Hazard FK, Lathi RB (2015) Pregnancy outcomes in women with chronic endometritis and recurrent pregnancy loss. Fertil Steril 104: 927-931. Link: https://bit.ly/2M13mEF

23. Lewis El, Brower M, Shamonki M (2013) Treatment of chronic endometritis in women with implantation failure improves implantation in subsequent embryo transfers. Fertil Steril 100: S390. Link: https://bit.ly/3sGdvr9

24. Bayer-Garner IB, Korourian S (2001) Plasma cells in chronic endometritis are easily identified when stained with syndecan-1. Mode Pathol 14: 877-879. Link: https://bit.ly/3sGRQ2g

25. Kannar V, Lingaiah HKM, Sunita V (2012) Evaluation of endometrium for chronic endometritis by using syndecan- 1 in abnormal uterine bleeding. J Lab Physician 4: 69-73. Link: https://bit.ly/2LRCsiJ

26. Hartman SK, Symons WA, Yeh T (2011) Chronic endometritis: How many plasma cells does it take to make the diagnosis? FASEB J 25: 1002-1013. Link: https://bit.ly/2XYs23f

\section{Discover a bigger Impact and Visibility of your article publication with}

\section{Peertechz Publications}

\section{Highlights}

* Signatory publisher of ORCID

* Signatory Publisher of DORA (San Francisco Declaration on Research Assessment)

* Articles archived in worlds' renowned service providers such as Portico, CNKI, AGRIS, TDNet, Base (Bielefeld University Library), CrossRef, Scilit, J-Gate etc.

* Journals indexed in ICMJE, SHERPA/ROMEO, Google Scholar etc.

* OAI-PMH (Open Archives Initiative Protocol for Metadata Harvesting)

* Dedicated Editorial Board for every journa

* Accurate and rapid peer-review process

* Increased citations of published articles through promotions

* Reduced timeline for article publication

Submit your articles and experience a new surge in publication services (https://www.peertechz.com/submission).

Peertechz journals wishes everlasting success in your every endeavours.

Copyright: ㄷ 2021 Elnashar AT, et al. This is an open-access article distributed under the terms of the Creative Commons Attribution License, which permits unrestricted use, distribution, and reproduction in any medium, provided the original author and source are credited.

Citation: Elnashar AT, Sabry M (2021) Chronic endometritis in In-Vitro fertilization failure patients. Glob J Fertil Res 6(1): 001-005

DOI: https://dx.doi.org/10.17352/gjfr.000018 